\title{
Flight Dynamics and GN\&C for Spacecraft Servicing Missions
}

\author{
Bo Naasz ${ }^{1}$ \\ NASA Goddard Space Center, Greenbelt, MD \\ Doug Zimpfer and Ray Barrington ${ }^{2}$ \\ Draper Laboratory, Houston, TX, 77058 \\ and \\ Tom Mulder ${ }^{3}$ \\ Boeing Space Operations and Ground Systems, Houston, TX, 77062
}

\begin{abstract}
Future human exploration missions and commercial opportunities will be enabled through in-space assembly and satellite servicing. Several recent efforts have developed technologies and capabilities to support these exciting future missions, including advances in flight dynamics and Guidance, Navigation and Control. The Space Shuttle has demonstrated significant capabilities for crewed servicing of the Hubble Space Telescope (HST) and assembly of the International Space Station (ISS). Following the Columbia disaster NASA made significant progress in developing a robotic mission to service the HST. The DARPA Orbital Express mission demonstrated automated rendezvous and capture, in-space propellant transfer, and commodity replacement. This paper will provide a summary of the recent technology developments and lessons learned, and provide a focus for potential future missions.
\end{abstract}

\footnotetext{
${ }^{1}$ NASA Aerospace Engineer, Goddard Space Flight Center 800 Greenbelt Rd Greenbelt MD 20771

${ }^{2}$ Space Systems Associate Director, PFA, 17629 El Camino Real Suite 470 Houston, Tx 77058

${ }^{2}$ Space Systems Program Manager, PFA, 17629 El Camino Real Suite 470 Houston, Tx 77058

${ }^{3}$ Boeing Associate Technical Fellow; 13100 Space Center Blvd, HM6-10, Houston, TX 77059; AIAA Associate Fellow
} 


\section{Introduction}

potential game changing element of future exploration may be the ability to perform in-space assembly and servicing of spacecraft. Future exploration missions are likely to require some form of in-space assembly similar to the International Space Station (ISS) to assemble components for missions beyond Low Earth Orbit (LEO). The Hubble Space Telescope (HST) was designed to be serviced by the Space Shuttle and has demonstrated the significant benefits this capability provides, including correction of the original optics, replacement of failed components, and upgrades to the science instruments and capabilities. Future space exploration could benefit from the lessons of HST. For example, if the vehicles developed for human exploration provided the capability to capture and service other spacecraft, future generations of science missions could rely on these capabilities to provide similar benefits to those realized by the HST. Additionally, the ability to service, repair, or refuel elements of a system-of-system exploration infrastructure would significantly enhance reliability and functionality.

Flight dynamics and guidance, navigation and control (GN\&C) capabilities are essential to enable future spacecraft servicing applications, including providing the capability to rendezvous with and capture the spacecraft to be serviced, controlling attitude of the mated configurations, and repositioning/reboosting the combined configurations. To achieve these capabilities significant development has been conducted over the past twenty years. These efforts include the development of the GN\&C necessary to service the Hubble Space Telescope with the crewed Space Shuttle, the development of GN\&C for robotic servicing for the Defense Advanced Research Projects Agency (DARPA) Orbital Express (OE) demonstration and significant development for the Hubble Robotic Servicing and Deorbit Mission (HRSDM), and the DARPA SUMO project. Although, these efforts have demonstrated many of the capabilities necessary for future demonstration missions, new capabilities may provide benefits to future servicing concepts.

This paper will provide a summary of the GN\&C capabilities developed for several of these recent servicing missions. The critical new capabilities developed and demonstrated will be reviewed, and important lessons learned from these missions will be summarized. Finally, the paper will place these developments and lessons learned in context of potential future servicing concepts and provide potential technologies that could be developed. 


\section{Space Shuttle Servicing Experience}

Following initial deployment of the HST, five servicing visits were performed by the Space Shuttle and attending crew. These missions were highly successful at replacing or repairing failed or outdated components (science instruments, reaction wheels, solar arrays, computers, batteries, thermal blankets, etc) many of which were not initially intended for servicing. However, the combined HST design, access to the inner compartments of the bus, ground planning, tool design, training, the agility of humans in space, and the capability of the Space Shuttle allowed for the repair, upgrade, and life extension of HST.

As with Shuttle experience and specifically HST servicing it is clear that initial design requirements typically do not consider all the possibilities and opportunities of the future. The Shuttle design only included six vernier jets to provide temporary rotational control for support of microgravity payloads. The Shuttle's 38 primary jets at 14 different positions provided redundancy and control for six degrees of freedom. In practice, the vernier jets are used almost exclusively for support of payloads primarily for the cause of minimizing imparted loads. Although there was initially no vernier translation the Shuttle program has found cleaver means to use the vernier jets for altitude adjustments (reboost). The lack of vernier redundancy or translation capability has incurred expense to the Shuttle program and HST project alike.

Likewise the design of HST imposed complication and costs that could have been avoided. The support structure for attaching the HST to the Shuttle did not adequately isolate the HST from the loads imparted during the reboost of HST. Several modifications, mitigations and upgrades all acted to make this better over time. Second, the initial Solar Array (SA) design did not tolerate loads imparted by the Shuttle's control system. This concern was resolved with installation of new rigid SAIII's during the Servicing Mission SM-3B.

\section{A. HST Reboost}

One of the primary services provided by the Shuttle to HST is altitude maintenance burns (reboosts) imparted to overcome the effects of orbital decay. Changes in configuration of the HST and increased capability of the Shuttle made this task easier over time. The first reboost was executed with the HST tilted forward at 45 degrees on the Berthing and Positioning System (BAPS) and used the Shuttle's $-X$ primary jets. Servicing mission 2 used manual techniques to continually fire the Shuttle's vernier jets to achieve the required delta-V. For the later servicing mission 3B and 4, the automatic reboost capability that was developed for the ISS was utilized.

For STS-32/SM-1, much work was done to explore all translation options against plausible uncertainties with the objective to minimize impact to the HST. At the time, use of the Shuttle vernier jets was not considered as the Shuttle Digital AutoPilot did not support a translation mode that could be commanded directly. Preflight analysis eventually yielded a conclusion that the lowest imparted loads to the HST pivot interface using the Shuttle's primary jets would be achieved by using the $-\mathrm{X}$ (forward firing) jets and the HST pivoted at 45 degrees. The biggest factor in this conclusion was the desire to avoid resonating the HST pitch pivot mode at $0.10-0.11 \mathrm{~Hz}$. The more natural choice using $+\mathrm{X}$ (aft firing) jets had thrust aligned nearly through the composite Center of Gravity (CG) that would result in slow attitude excursions and thus low frequency rate limit corrections. Caution then dictated that the analysis consider the attitude rate correction firings to align to the HST pivot mode resulting in near violation of the limit. The $-\mathrm{X}$ jet thrust was less aligned with the $\mathrm{CG}$ resulting in a higher frequency of attitude rate corrections that were not expected to resonate the HST pivot mode. In practice, the flight reboost yielded even higher pitch torque from the $-\mathrm{X}$ translation firings than expected which caused not only rate corrections but attitude deadband corrections as well. The performance discrepancy was traced to discovery that the self impingement of the Shuttle $\mathrm{X}$ jets was incorrectly modeled in the Shuttle Operational Data Book (SODB). Post flight analysis determined that the attitude deadband firings during the STS-32 reboost were of higher frequency than the expected rate corrections and did not significantly contribute to the loads. As a result of the self impingement modeling error discovery the Shuttle K-loads and all future simulation models were updated to accurately represent the $-\mathrm{X}$ jet firings.

By the time of the next visit to HST, STS-82, a new concern had been identified. The solar arrays on the HST were taught to the extent that the bistem supports bent in opposite directions to cause a twist in the blanket support structure, see Figure 1 - HST Solar Arrays II(left) III(right)Figure-2 - HST Sular-Array's-H(left) III(right). A new observation criteria and constraint was placed on the Shuttle control in servicing of the HST. All Shuttle control, 
including reboost, was to be exercised such that the peak to peak deflection at the tip of the SA bi-stems would be less than 2 inches. Clearly the $-\mathrm{X}$ reboost that had been used for servicing mission 1 would not satisfy this criteria. A new approach was developed whereby the two aft left and right vernier jets were deselected such that a rotation yaw command to Shuttle control would yield two down firing aft jets and one down firing forward jet. It was therefore possible to achieve a translation in Shuttle $-\mathrm{Z}$ direction by manually commanding a yaw rotation. As a yaw command yields yaw rate, pure translation was achieved by toggling between plus and minus yaw to keep rotation rates and attitude excursions within reasonable boundaries. In practice the vernier yaw toggling technique resulted in only slight violations of the 2" tip deflection criteria while achieving reboost. The manual yaw procedure was executed four times during SM-2 achieving a total delta-V of 8 nautical miles (NM) achieving a $334 \times 321$ NM orbit.
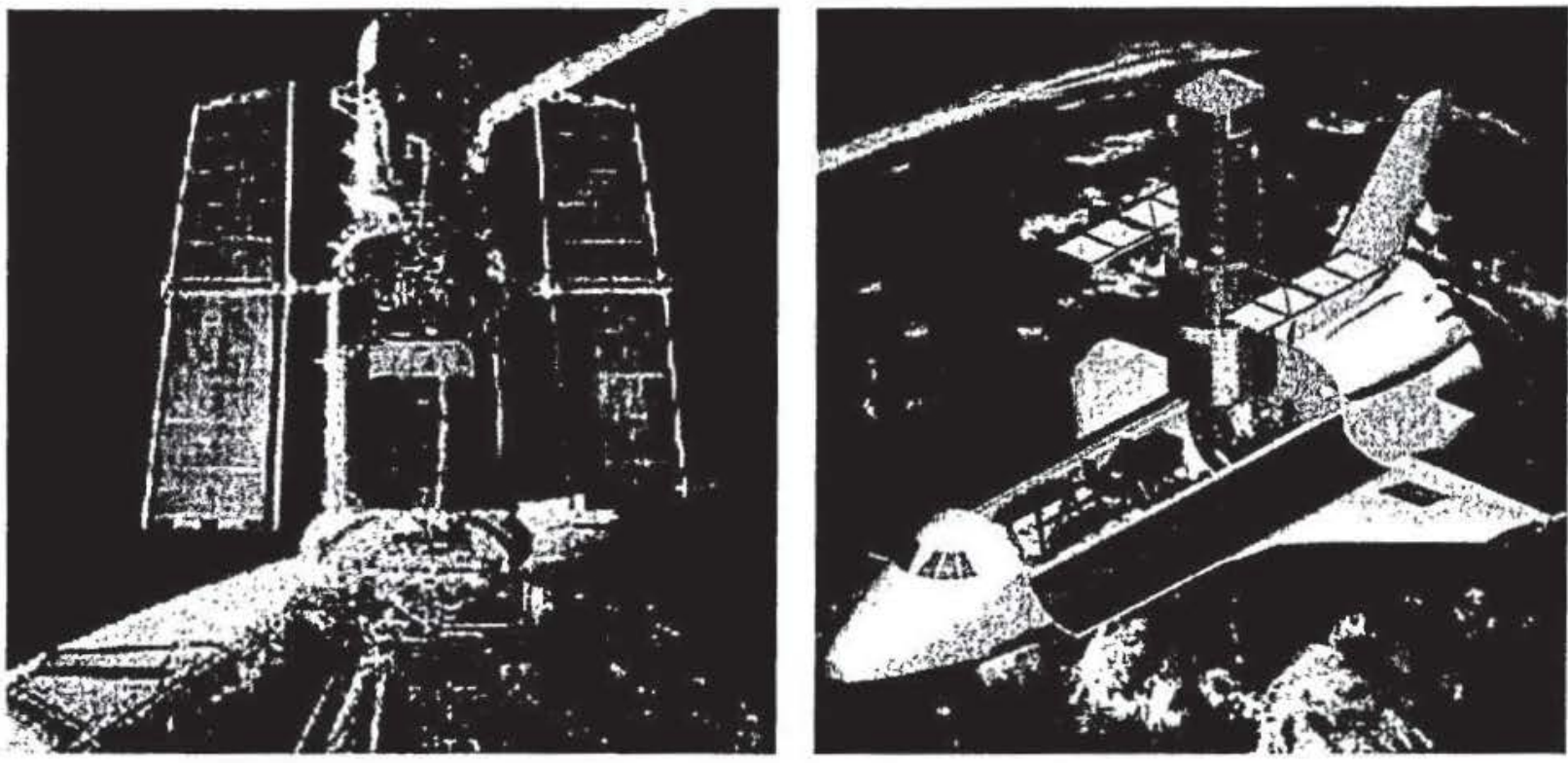

Figure $\underline{1} z$ - HST Solar Arrays II(left) III(right)

Later in the Shuttle program, an automatic reboost capability was added that allowed specific selection of jets to fire to accommodate translation. With this new capability, all four down firing vernier jets could be selected to fire simultaneously negating the need for manual yaw commanding procedure used for SM-2. The automatic reboost capability was used for the final two servicing missions to HST, STS-109/SM-3B and STS-125/SM-4.

\section{B. HST Design}

As mentioned before, the concern over bistem integrity of the SA imposed a less than 2" tip deflection criteria that resulted in significant analysis and constraints to Shuttle control. A top to bottom review of all the Shuttle control system effects whether commanded or incurred was conducted. Additionally, an exhaustive survey of jet performance from previous missions was conducted to assure that the forcing functions used to evaluated loads to the HST were adequately conservative. The result was a list of recommendations to soften the impact of the Orbit Digital Auto Pilot (DAP) to the HST. Figure 2- DAP Recommendations to minimize tip deflectionsFigure-3-DAP Recommendations to-minimize tip deflections presents the table of recommendations that was derived to address the tip defection concern. 


\begin{tabular}{|l|l|}
\hline \multicolumn{1}{|c|}{ Problem } & \multicolumn{1}{c|}{ Solution } \\
\hline Maneuver Cycles & $\begin{array}{l}\text { Widen Deadbands }(1.0 \rightarrow 3.0) \\
\text { Lower maneuver rate }(0.2>0.1 \text { or lower }) \\
\text { Use small rate limit }(0.02)\end{array}$ \\
\hline OPS moderecall & $\begin{array}{l}\text { Avoid recalls during critical OPS } \\
\text { Select FREE drift during recall. }\end{array}$ \\
\hline $\begin{array}{l}\text { Short maneuvers post } \\
\text { FREE drift }\end{array}$ & $\begin{array}{l}\text { Avoid during critical OPS. } \\
\text { Lower maneuver rate }\end{array}$ \\
\hline $\begin{array}{l}\text { Maneuver startup and } \\
\text { terminate transients. }\end{array}$ & Lower maneuver rate. $(0.2>0.1$ or lower $)$ \\
\hline
\end{tabular}

Figure 23- DAP Recommendations to minimize tip deflections

The recommendations drove new procedure development, elevated training costs and raised the risk of mistakes being made. Figure 3-DAP Recommendation and Constraints Figutre-4-DAP Recemmendation-and-Constraints presents the orbit DAP constraints matrix for Remote Manipulator System (RMS) operations citing Deadbands (DB), Rate Limits (RL), Maneuver Rates (MR), RMS modes Position Hold (PH), or Brakes On to mitigate concerns with SA tip deflections.

\begin{tabular}{|c|c|c|c|c|}
\hline & $\begin{array}{c}\text { RISS Brakes ON } \\
\text { IRCS } \\
\text { DB } Z 2 \text { deg } \\
\text { IIR } \leq 0.1 \text { deg } / \mathrm{sec}\end{array}$ & $\begin{array}{c}\text { RIIS Position Hold } \\
\text { IRCS } \\
\text { DB } \geq 2 \mathrm{deg} \\
\text { IIR } \leq 0.1 \mathrm{deg} / \mathrm{sec}\end{array}$ & $\begin{array}{c}\text { RIIS Brakes Oa } \\
\text { Alt Tall Only } \\
2 \text { jets, } 0.08 \text { pulse } \\
\text { delay } 7.5 \mathrm{sec} \\
\mathrm{MT}=0.05-0.1 \mathrm{deg} / \mathrm{s} \\
\text { RL }-0.1 \mathrm{deg} / \mathrm{s}\end{array}$ & $\begin{array}{c}\text { RIIS Position Hold } \\
\text { Alt Tail Only } \\
2 \text { jets, } 0.08 \mathrm{pulse} \\
\text { delay } 7.5 \mathrm{sec} \\
\mathrm{IRR}=0.05-0.1 \mathrm{deg} / \mathrm{s} \\
\mathrm{RL}=0.1 \mathrm{deg} / \mathrm{s}\end{array}$ \\
\hline $\begin{array}{l}\text { CAP-REL } \\
\text { CA-1 }\end{array}$ & $\begin{array}{l}\text { Tip deflections } \\
\text { Moderate to High } \\
R L \geq 0.05 \mathrm{deg}^{\prime} \mathrm{s}\end{array}$ & $\begin{array}{c}\text { Tip deflections } \\
\text { Low } \\
R I \geq 0.05 \text { deg's } \\
D B \geq 2 \text { deg }\end{array}$ & $\begin{array}{c}\text { Tip deflections } \\
\text { Noderate } \\
\mathrm{DB}=3 \text { deg } \\
\mathrm{MR}=0.1 \mathrm{deg}^{\prime} \mathrm{s}\end{array}$ & $\begin{array}{c}\text { Tip deflections } \\
\text { Low } \\
\mathrm{DB} \geq 3 \text { deg } \\
\mathrm{M} R \leq 0.1 \mathrm{deg} \cdot \mathrm{s}\end{array}$ \\
\hline $\begin{array}{l}\text { Pre-Release } \\
\text { (Deadband } \\
\text { Collapse) } \\
\text { C.A=1 }\end{array}$ & $\begin{array}{l}\text { Tip deflections } \\
\text { Moderate } \\
\text { RL } 20.05 \text { deg's } \\
\text { DB }=2 \text { deg } \\
\text { MIR }=0.024 \text { deg's }\end{array}$ & $\begin{array}{c}\text { Trp deflections } \\
\text { Low } \\
\text { RI }=0.03 \text { deg's } \\
\mathrm{DB}=0.5 \text { deg } \\
\mathrm{MIR}=0.024\end{array}$ & $\begin{array}{l}\text { Tip deflections } \\
\text { Mloderate } \\
\text { Not Recommended }\end{array}$ & $\begin{array}{c}\text { Tip deflections } \\
\text { Low } \\
D B=2 \text { deg } \\
M R=0.05 \text { deg s }\end{array}$ \\
\hline $\begin{array}{l}\text { Ext Park } \\
\text { CA-2 }\end{array}$ & $\begin{array}{l}\text { Tip deflections } \\
\text { Moderate to High } \\
\text { RL } \geq 0.05 \text { deg's }\end{array}$ & $\begin{array}{l}\text { Ty deflections } \\
\text { Low } \\
\text { RI } \geq 0.05 \text { deg's } \\
\text { DB } 22 \text { deg }\end{array}$ & $\begin{array}{l}\text { Tip deflections } \\
\text { Moderate } \\
D B \geq 5 \text { deg } \\
\text { MR }=0.1 \text { deg s }\end{array}$ & $\begin{array}{c}\text { Tip deflections } \\
\text { Low } \\
\mathrm{DB} \geq 5 \text { deg } \\
\mathrm{M} \mathrm{R} \leq 0.1 \text { deg'sec }\end{array}$ \\
\hline $\begin{array}{l}\text { Hover } \\
\text { CAIm }\end{array}$ & $\begin{array}{l}\text { Tip deflections } \\
\text { Moderate to High } \\
\text { RL } 20.10 \mathrm{deg} \text { 's }\end{array}$ & $\begin{array}{l}\text { Tip deflections } \\
\text { Low } \\
\text { RI } \geq 0.05 \text { deg's } \\
\text { DB } \geq 2 \text { deg }\end{array}$ & $\begin{array}{l}\text { Tip deflections } \\
\text { Moderate } \\
\text { DB } 25 \text { deg } \\
\mathrm{MR}=0.1 \mathrm{deg} / \mathrm{s}\end{array}$ & $\begin{array}{c}\text { Tip deflections } \\
\text { Low } \\
D B \geq 5 \text { deg } \\
M R=0.1 \text { deg sec }\end{array}$ \\
\hline & $\begin{array}{c}\text { Avoid if } \mathrm{PH} \\
\text { Avalable }\end{array}$ & & $\begin{array}{l}\text { Tip deflection risk } \\
\text { accepted by GSFC }\end{array}$ & \\
\hline \multicolumn{2}{|c|}{$\begin{array}{l}\mathrm{DB}=\text { attitude deadband } \\
\mathrm{RI}=\text { rate limit } \\
\mathrm{MR}=\text { maneuver rate } \\
\mathrm{CA}=\mathrm{CNTL} \mathrm{ACCEL}\end{array}$} & & \multicolumn{2}{|c|}{$\begin{array}{l}\text { Acceptable deflections } \leq 2 \text { inches } \\
\text { Low deflections: } 2-4 \text { inches } \\
\text { Moderate deflections: } 4-5 \text { inches } \\
\text { High deflections: }>8 \text { inches }\end{array}$} \\
\hline
\end{tabular}

Figure 34 - DAP Recommendation and Constraints

The suspect SA's were replaced with more rigid SAIII's during STS-109/SM-3B; this design change benefited analysis and procedures for STS-125/SM-4.

\section{Observations}

To be successful at robotic servicing in the future, we must draw on the lessons learned from our experiences in human attended servicing as well as our robotic experience. The tools and methods developed for repairing or replacing critical spacecraft components will have to be improved and employed without the aid of on-site humans. This will create new and unique challenges in spacecraft design both for the serviced and servicing vehicles. 
In hindsight, more foresight of potential services provided by the Shuttle and tolerance by HST to servicing vehicle could have avoided the complication and costs associated with HST servicing. This lesson should therefore be applied during the conception and design of new spacecraft. Spacecraft design in the future at a minimum should not arbitrarily preclude or block capability and should consider accommodating servicing from current and projected capabilities. 


\section{Hubble Robotic Servicing and Deorbit Mission}

Following the Columbia disaster in 2003, NASA determined it was unsafe to send a human crew to perform the final servicing mission to the HST. To avoid the loss of the HST, either due to gradual decay of its orbit or additional failure of its components, an effort was initiated to study concepts for a robotic servicing mission. In October 2004, NASA formed a team with the GSFC, MD Robotics, and Lockheed Martin to develop a robotic servicing mission. The Lockheed Martin led team included Aerojet providing propulsion systems, Ball Aerospace supporting the science instruments, Draper Laboratory leading the GN\&C development, Jackson and Tull supporting HST systems, MD Robotics providing sensors and robotics, and Orbital Sciences providing berthing interface support. The Hubble Robotic Vehicle (HRV) consisted of the Ejection Module (EM), Deorbit Module (DM or HRVDM), AR\&D systems, and robotic servicing components, shown in Figure 4 - Hubble Robotic Vehicle[Web Page]Figure-5 - Hubble-Robotic Vehicle[Web Page]. The EM provided storage of the science instruments, interfaced to the robot systems and provided communications, propulsion and reaction wheels. The DM was responsible to provide the Autonomous Rendezvous and Docking (AR\&D) and the capability for deorbit at the end of HST life.

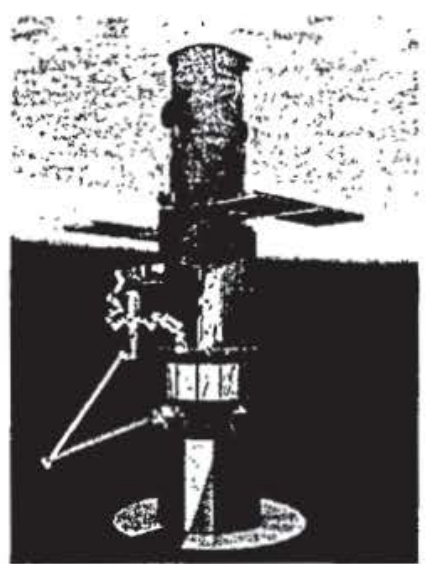

Figure 45 - Hubble Robotic Vehicle[Web Page]

The ambitious mission concept (see Figure 5 HRSDM Concept of OperationsFigure-6 HRSDM Concept of Operations) required the HRV to rendezvous and capture the HST, including in the event of an uncontrolled HST, perform a hard mate with the HST through the capture bars at the base of the HST, and then perform a series of complex robotic servicing operations using the Special Purpose Dexterous Manipulator originally developed for the ISS. Following completion of the servicing operations, the EM would demate from the HST, separate, and perform a controlled reentry/disposal. The DM would remain attached to the HST providing the capability to reboost and then deorbit the HST following completion of its science mission. The focus of the remainder of this section will be on the flight dynamics and GN\&C functions of the HRSDM concepts and the technologies developed to support the complex mission requirements. The HRSDM concept provided a challenging set of requirements including:

- Rendezvous and capture with a sensitive, high-value spacecraft

- Rendezvous and capture with a potentially tumbling/passive spacecraft

- Robotic capture with a manipulator

- Automated docking to three-bar mechanism

- Single fault tolerance for reliability, including dual independent mating methods 


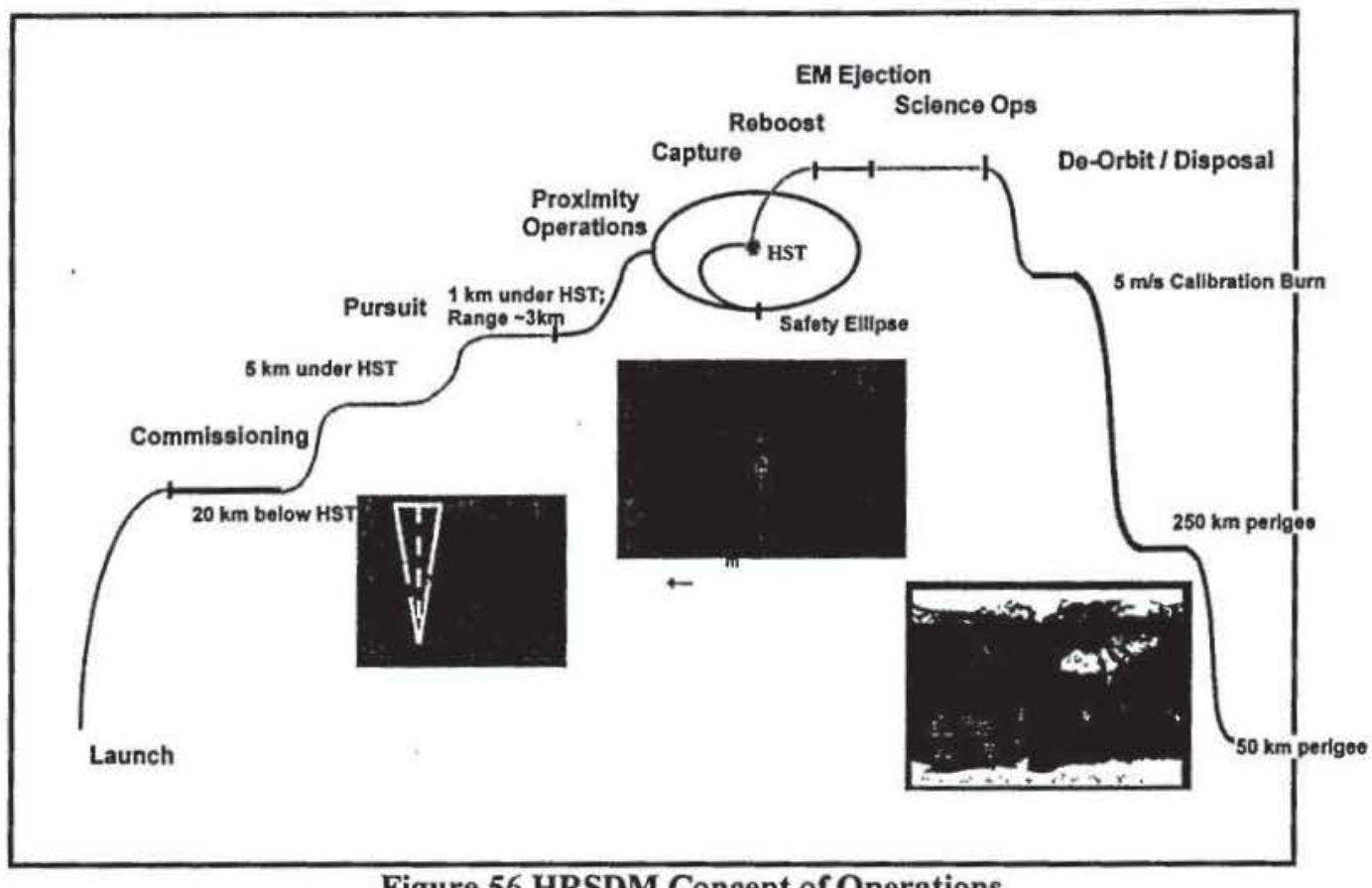

Figure 56 HRSDM Concept of Operations

\section{A. HRVDM System Architecture}

The primary functions of the HRVDM were to provide the capability for rendezvous and capture and end-of-life deorbit. The GN\&C functional architecture is provided in Figure 6-GN\&C Functional Architecturefigure-7GN\&E Funetional Arehitecture. A key element of the mission was selection of the sensor suite for AR\&D. Although the HST was designed to be serviced by the Space Shuttle, it was not designed for cooperative AR\&D; therefore, the sensor suite had to function without the benefit of cooperative target features such as reflectors. Additionally, the mission included requirements to rescue a disabled or tumbling HST, requiring that the sensor suite also provide full pose (relative position and attitude measurements). The pose algorithms were required to

identify the initial orientation of a tumbling HST. Figure 7 - GN\&C Sensor SuiteFigure 8- GN\&:C Sensor-Stite provides the sensor suite selected for the robotic mission. The suite consisted of a series of LIDAR and optical sensors. Image processing algorithms were to be employed to utilize known features of the HST to determine pose. A critical element of the sensor capabilities was the acquisition range for the LIDAR sensor. Longer range acquisition provides adequate time for sensor performance assessment and adequate incorporation of sensor measurements into the navigation system prior to initiating the burns necessary to bring the HRVDM within proximity to the HST. 
GN\&C Functional Architecture

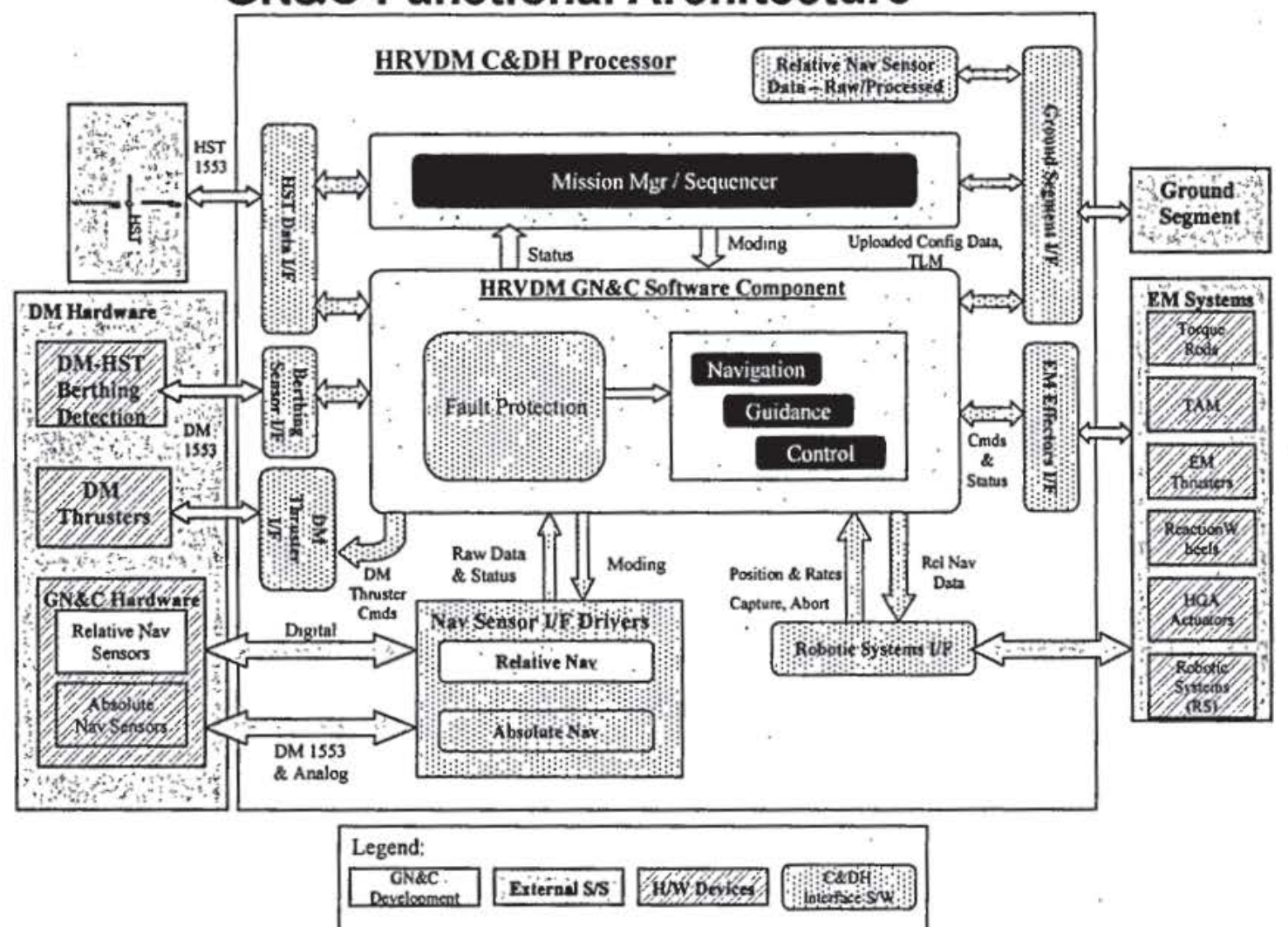

Figure 6 7 - GN\&C Functional Architecture

\begin{tabular}{|c|c|c|c|c|c|}
\hline \multirow{2}{*}{ Sensor } & \multirow{2}{*}{$\begin{array}{c}\text { Pursuit } \\
(>150 \mathrm{~m})\end{array}$} & \multicolumn{3}{|c|}{ Prox Ops } & \multirow{2}{*}{$\begin{array}{l}\text { Capture } \\
(\sim 0.3 \mathrm{~m})\end{array}$} \\
\hline & & $<150 m$ & $<50 m$ & $<30 m$ & \\
\hline \multirow{7}{*}{$\begin{array}{l}\text { Natural } \\
\text { Feature } \\
\text { Camera }\end{array}$} & Ervas & & Whats & 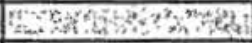 & 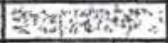 \\
\hline & 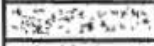 & & $5 \times 2$ & 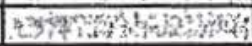 & 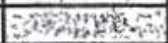 \\
\hline & Why & 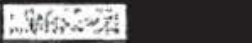 & & & Whases? \\
\hline & 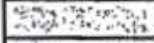 & 20 & & & Hinos \\
\hline & $5 x^{2}+x^{2}$ & Hostow & 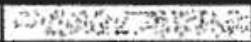 & 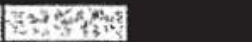 & \\
\hline & Whants & 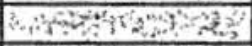 & 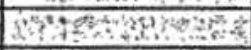 & 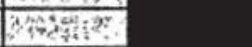 & \\
\hline & bystom & 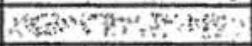 & 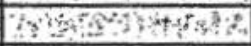 & 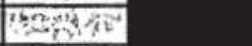 & \\
\hline \multirow{2}{*}{$\begin{array}{c}\text { Laser } \\
\text { Camera }\end{array}$} & Zny & 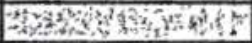 & 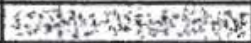 & Fexpm & \\
\hline & gyones? & 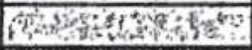 & Bow & $4 x$ & \\
\hline LIDAR & & & & & 8 \\
\hline
\end{tabular}

Figure 78 - GN\&C Sensor Suite

\section{B. HRVDM Capture Operations}

Capture of the HST was a mission critical function of the HRSDM. Two independent capture methods were incorporated, both direct docking to the servicing towel bars at the base of the HST and grapple via a robotic manipulator similar to the Shuttle robot arm. The GN\&C mission trajectory concept was developed to rendezvous with the HST and place the HRVDM into safety ellipse orbit in proximity to the HST. This passively safe orbit provided the necessary time in proximity to the HST to determine its orientation in the event it had lost power and/or control. Nominal capture of the HST followed a profile very similar to the Shuttle HST profile. 
In the event of the need to capture a tumbling HST, the onboard optical systems would be used to determine the relative orientation between the two spacecraft. Once the orientation of the HST had been determined, an approach trajectory would be determined by the ground to align the HRVDM orientation with the HST at the appropriate time. The HRVDM would then be command to perform a Constant Line of Site (CLOSR) approach to the HST, Figure 8 CLOSR GuidanceFigure- - CLOSR-Guidance. The CLOSR guidance was a new capability developed to support the HRSDM.
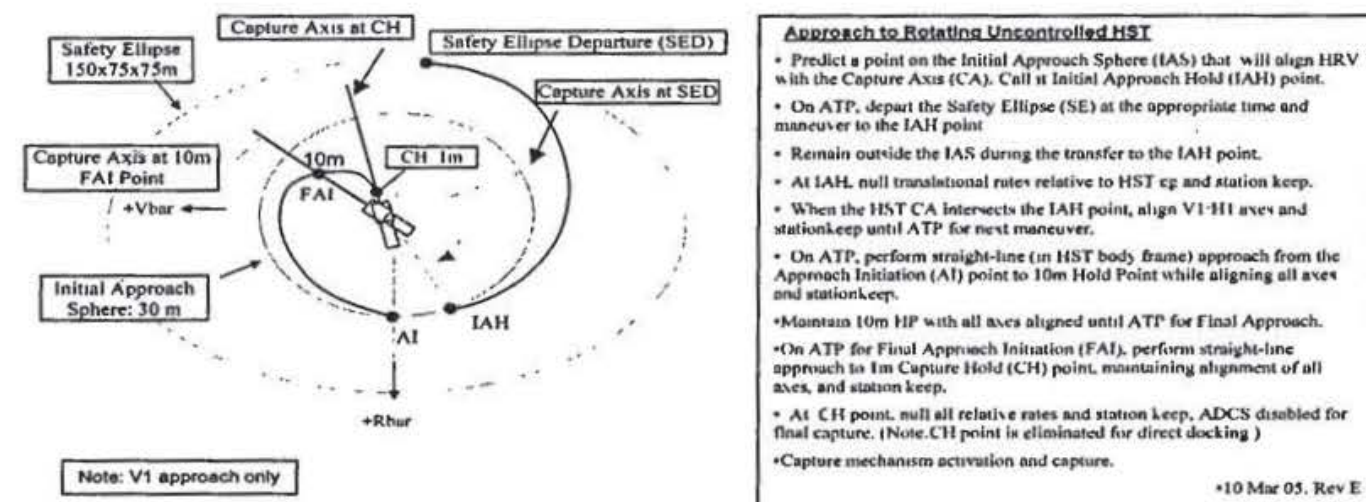

-10 Mar 09. Rev E
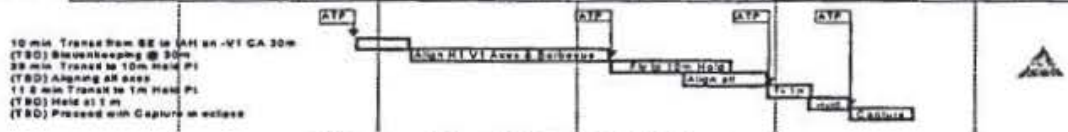

Figure $\underline{8} 9$ - CLOSR Guidance

Both of the capture techniques imposed stringent performance requirements on the GN\&C. The capability for the control system to precisely align all three towl bars simultaneously allowed for minimal control margins. Additionally, precise control of the HRVDM base was required to assure that the tip of the robotic arm was maintained adequately within its capture box prior to initiating automatic capture operations, given the significant offset from the vehicle center of gravity to the tip of the robotic arm. Figure 9-Sample Capture Control System PerformanceFigure-10-Sample-Capture-Control-System Performance provides a sampling of the control system performance.
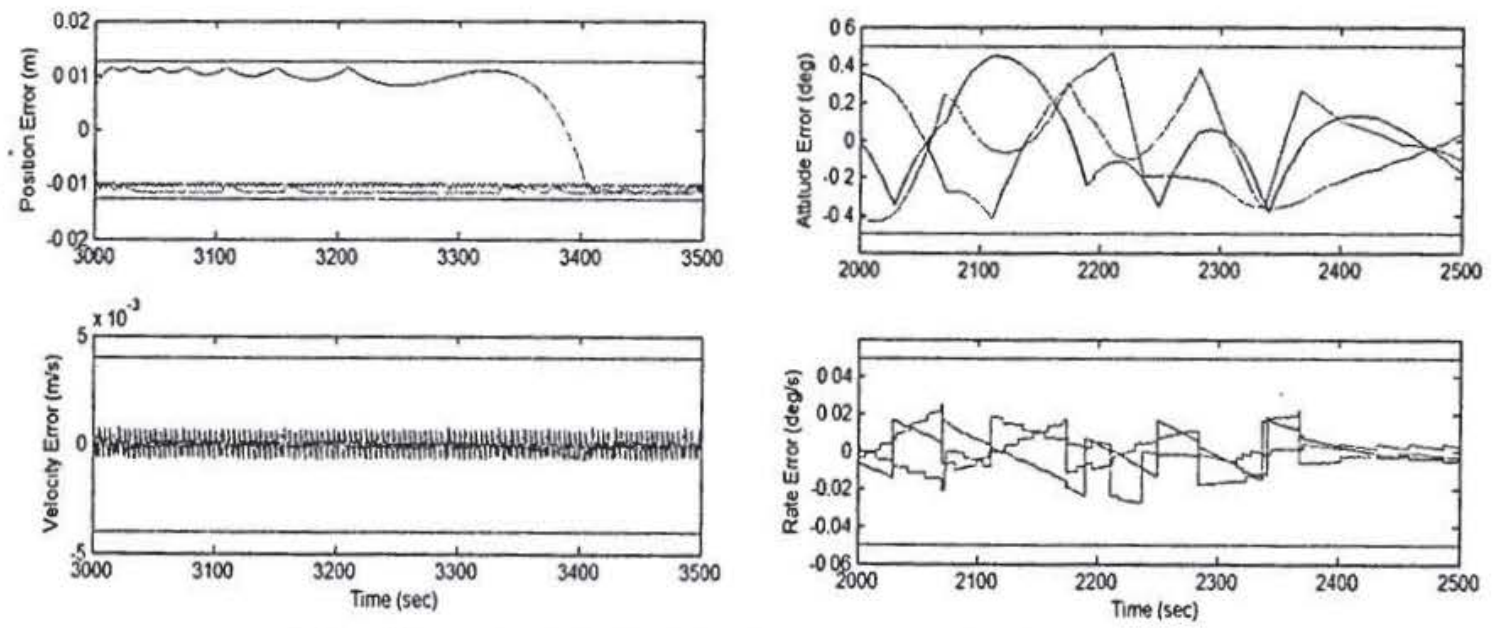

Figure 910 - Sample Capture Control System Performance

\section{HRVDM Mission Management}


A final element of the HRVDM GN\&C system was the development of concepts and software for automated mission management. The concept chosen was for the onboard system to automatically execute a series of tasks preselected by the ground operators. In this fashion the ground would remain in control of the overall mission planning functions, while the onboard system was responsible for automatic execution of the necessary activities to perform the desired tasks. Additionally, the onboard system incorporated the necessary onboard fault protection algorithms to monitor the performance of the GN\&C as it proceeded with the mission and determine if an anomaly had occurred and safe the vehicle. Unlike typical satellite systems, safing the vehicle was mode dependent and at times complex. The most significant complexity was resolving the time sequences and priorities for actions should a problem occur during the final mating operations. Figure 10-Mission Manager Architecturefigure-11-Mission Aanager-Architeettre provides the mission manager architecture.

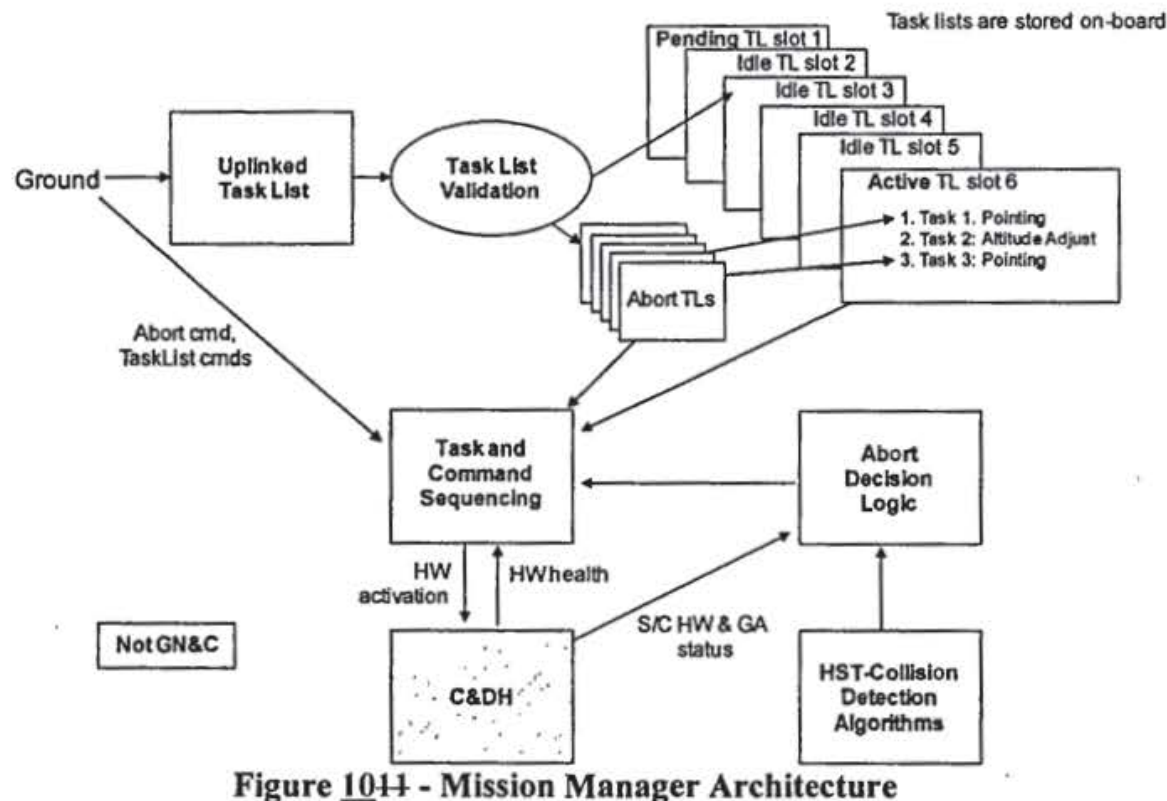




\section{Orbital Express}

$\mathrm{OE}$ was an on-orbit flight test program that successfully demonstrated autonomous rendezvous and capture (AR\&C) without assistance from the ground or target satellite. Multiple refueling demonstrations were also performed, prior to initial orbital separation of the two spacecraft, and following each of 5 captures. A robotic arm transferred a battery back-and-forth between spacecraft, and an operational computer was removed and replaced. These operations were demonstrated individually and in combination, without ground assistance.

OE was managed by DARPA, with additional sponsorship by NASA. Boeing Advanced Systems was prime contractor and funded new technologies in vision-based satellite tracking, advanced guidance, and autonomous navigation.

\section{A. Objectives and Technologies}

Satellite servicing can include replacement of failed components and replenishment of depleted propellant. The servicer may also provide orbital assistance, such as reboost or attitude control of an attached satellite. It is a costly

investment for a company to pursue a new line of satellites built with the design and interfaces necessary to accommodate these operations. That investment can be a showstopper if it carries a real or perceived risk of mission success, due to cost and technical difficulties involved in executing AR\&C and servicing operations. OE targeted the

technologies needed to eliminate these risks, then proved them in the only laboratory where true validation can occur - in earth orbit. Thus, the technical risks of AR\&C, component change-out, refueling, and orbital control were reduced; paving the way to a new breed of government and commercial satellites with servicing in mind. $\mathrm{OE}$ program objectives, autonomous technologies, and final schedule are summarized in

Figure 11 - OE Develoned and Flight-Tested Technologies from Late 2000 to Julv 2007Figtwe-12 OE Developed and Filight-Tested Technologies from tate 2000 to July 2007.
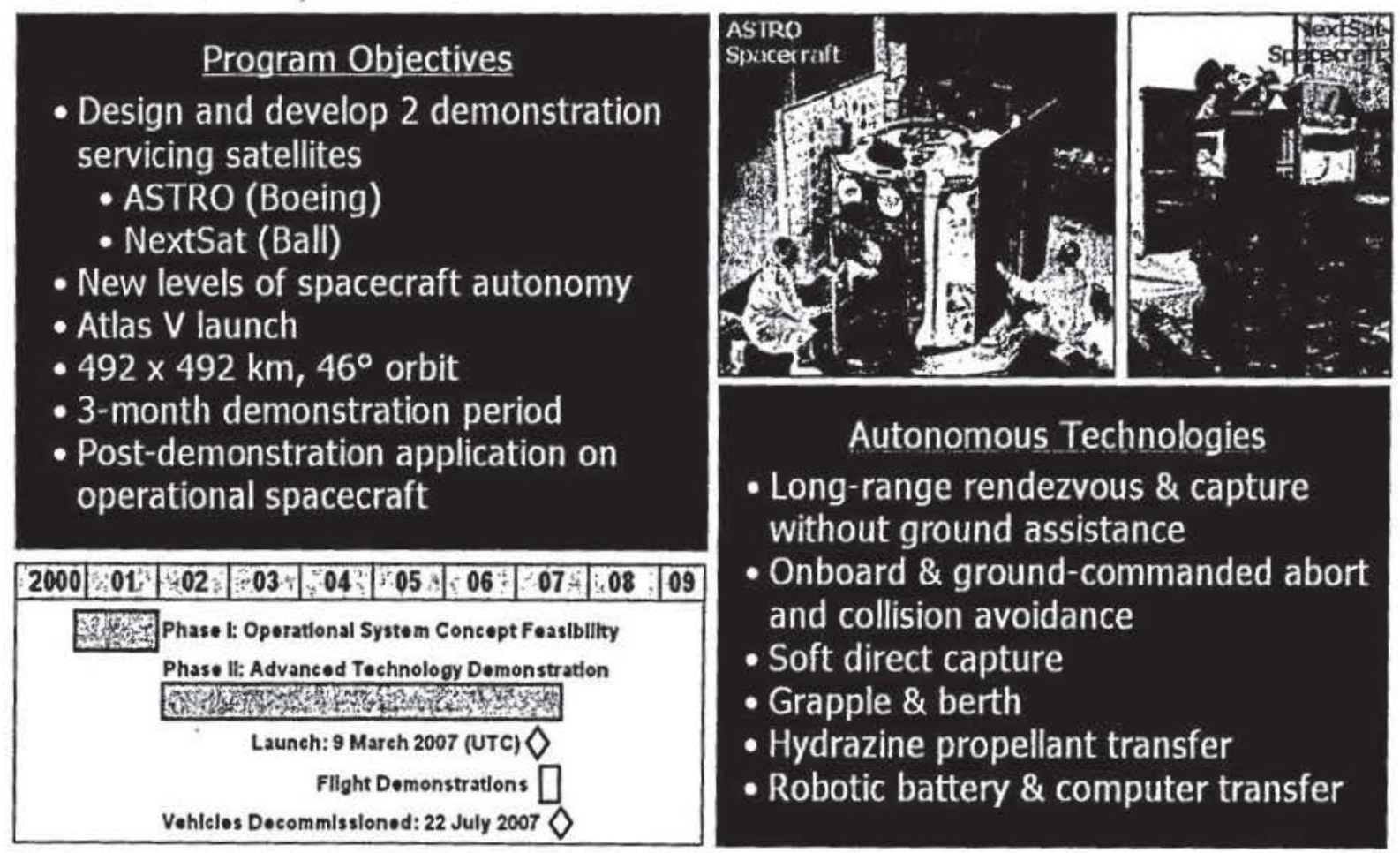

Figure 1112 - OE Developed and Flight-Tested Technologies from Late 2000 to July 2007

During mated operations, OE focused on systems, software, and interfaces for satellites designed for servicing. While the robotic arm and certain subsystems can be adapted to fixing or refueling existing satellites, that was not a purpose for the program. For example, the arm software and end effector required a compatible grapple fixture and 
target plate on the client satellite to perform capture. Grapple fixtures were needed on the replaceable battery and computer, and the propellant transfer system was designed from the ground-up as matched set on servicer and client (or fuel depot, depending on direction of Hydrazine flow).

Unmated operations were not constrained by such a limitation. While the Advanced Video Guidance Sensor (AVGS) did, in fact, require client-side retro-reflectors, other sensors carried a requirement to support rendezvous from long range to capture without dedicated design features built into the client satellite ${ }^{1}$. This was accomplished largely with Boeing-developed algorithms contained in the Vision-based Software for Track, Attitude, and Ranging (Vis-STAR), which computes azimuth, elevation, and range to the client. It also discerns roll, pitch, and yaw angles, provided the client has sufficient natural features. This approach differs from space shuttle dockings with the International Space Station (ISS), given ISS navigation aids in the form of retro-reflectors and a target cross. However, it is consistent with early shuttle missions that approached and captured non-cooperative satellites in existing orbits. Altogether different from shuttle, however, DARPA levied a requirement for the OE servicer to perform unmated operations entirely on it's own, with no one onboard and the ground behaving in a monitor and override mode, only (during periods with ground communications).

\section{B. Spacecraft}

The OE flight segment consisted of two spacecraft that were mated, stacked, and launched aboard a United Launch Alliance Atlas V rocket from Cape Canaveral Air Force Station, Space Launch Complex 41, on 8 March 2007. OE and four secondary payloads made up the Air Force Research Laboratory (AFRL) Space Test Program 1 (STP-1).

Boeing served as OE prime contractor, and designed and manufactured the chaser spacecraft, Autonomous Space Transport Robotic Operations (ASTRO), including the end-to-end guidance, navigation, and control (GN\&C) system. Ball Aerospace produced the Next Generation Servicable Satellite (NextSat), which served roles as both a satellite in need of repair and commodities depot (Figure 12 - ASTRO Views of NextSat during AR\&C Exercise \#4Figure 14-ASTRO-Views of NextSat during AR\&C Exercise \#4).

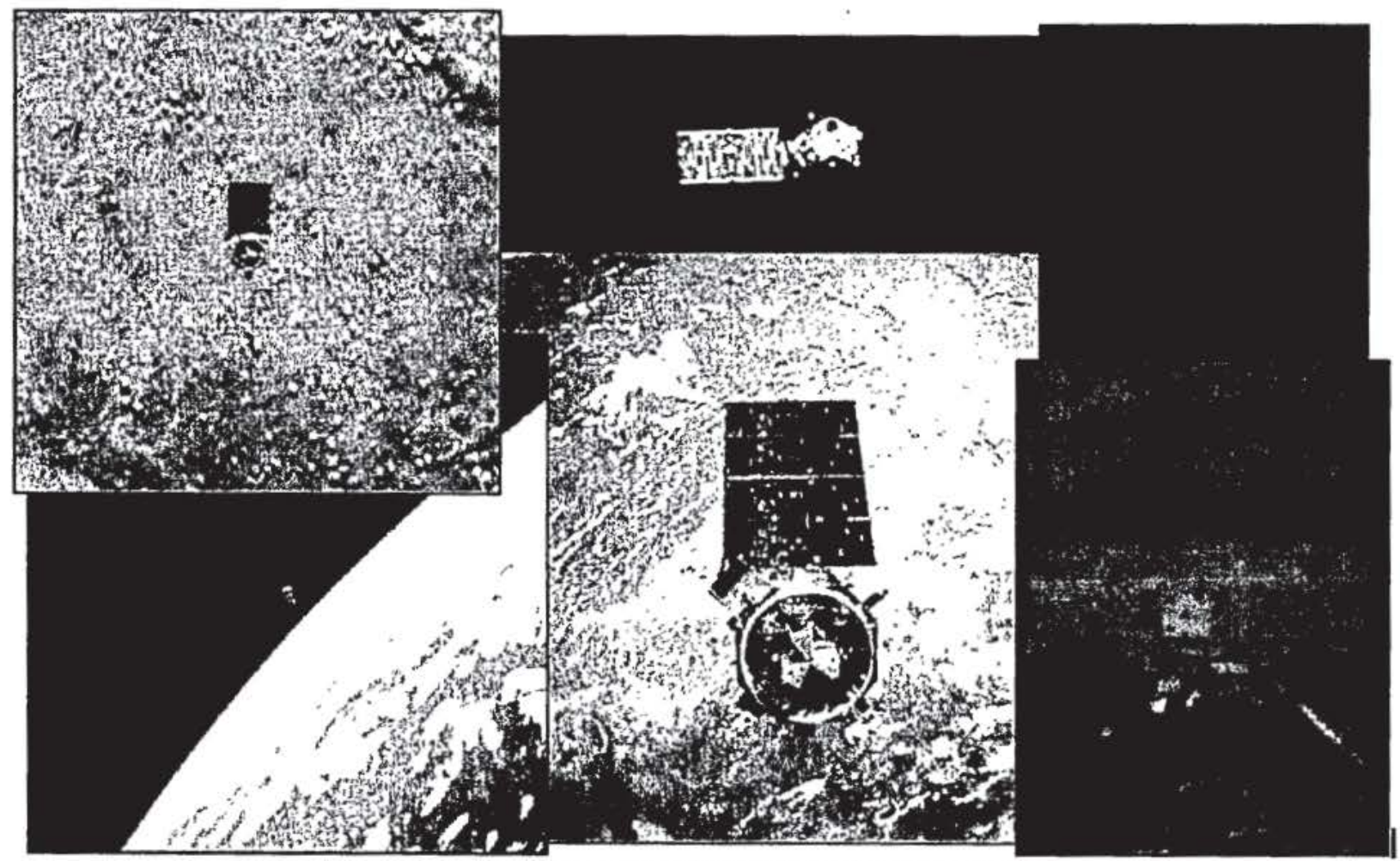

Figure 1214 - ASTRO Views of NextSat during AR\&C Exercise \#4 
Four other subcontractors participated on the $\mathrm{OE}$ team:

- Northrop Grumman Space Technology - Fluid Transfer and Propulsion Subsystem (FTAPS)

- MacDonald Dettwiler and Associates - Robotic arm

- Starsys Research Corporation - Soft capture mechanism

- Draper Laboratory - Onboard mission manager software

ASTRO and NextSat were deployed into a $492 \times 492 \mathrm{~km}$ orbit at $46^{\circ}$ inclination. Ground control was conducted at the AFRL Research, Development, Test, and Evaluation Support Center (RSC) at Kirtland Air Force Base in Albuquerque, New Mexico. An engineering support room was established at the Boeing facility in Huntington Beach, California, along with a rendezvous support room at Boeing Tower 2 in Houston, Texas.

\section{Mission}

An on-orbit test plan evolved during the six development years preceding flight, which combined many types and directions of rendezvous into seven AR\&C exercises. These were intended to validate autonomous approach, circumnavigation, stationkeeping, capture, and departure for a wide variety of conceptual orbits and servicing missions.

- Rendezvous from behind and in front of the client, from distances up to $410 \mathrm{~km}$

- Stable orbit and co-elliptic trajectories

- Two different stationkeeping algorithms, demonstrated at various sides and ranges $(4 \mathrm{~km}, 1 \mathrm{~km}, 500 \mathrm{~m}, 120 \mathrm{~m}$, $30 \mathrm{~m}, 10 \mathrm{~m}$, and $10 \mathrm{~cm}$ ) from the client

- Elliptical $( \pm 120 \times 60 \mathrm{~m})$ and near-circular $(100 \mathrm{~m})$ flyaround inspection of client at multiple orbital rates ( $1 \mathrm{x}$ and $3 \mathrm{x}$ )

- Day and night approach to, and capture of, the client in solar inertial (three times), +V-Bar, and -R-Bar attitudes

- Direct capture (3), and grapple/berth (2) of the client

- Day (2) and night (3) captures over range of solar beta angles $\left(3^{\circ}\right.$ to $\left.48^{\circ}\right)$

- Ground (AFSCN) and orbiting (TDRSS) communications access

- Onboard-commanded abort during approach (10 m range)

The test plan was a flexible template intended for modification as the flight unfolded, in response to real-time results. Changes to the flight plan were, in fact, implemented, following issues encountered during the second AR\&C exercise. Those issues resulted in an unintended expansion of exercise \#2 and check-off of additional AR\&C objectives, allowing a reduction in the number of exercises from seven to five. ASTRO motion relative to NEXTSat during the relatively complex Exercise \#5 rendezvous is shown in Figure 13 - Exercise \#5 Actual/Onboard In-

Plane Rendezvous Trajectoryfigure-15-Exercise 15 -Actual/Onboard In-Plane-Rendezveus Trajectery, and proximity operations in

Figure 14- Exercise \#5 Actual/Onboard In-Plane Proximity Operations Trajectoryfigure-16-Exercise-\#5 Actual/Onbeard-In-Plane-Proximity-Operations-Trajectory. The colored trajectory data was downlinked during periods of ground contact.

A sixth and entirely new exercise was appended to the end of the flight, culminating in separate orbits that would guarantee the trajectories would never cross again. With two healthy spacecraft remaining, the OE program was terminated, having completed all mission objectives and learned a great deal - both from successes and unanticipated problems encountered along the way. 


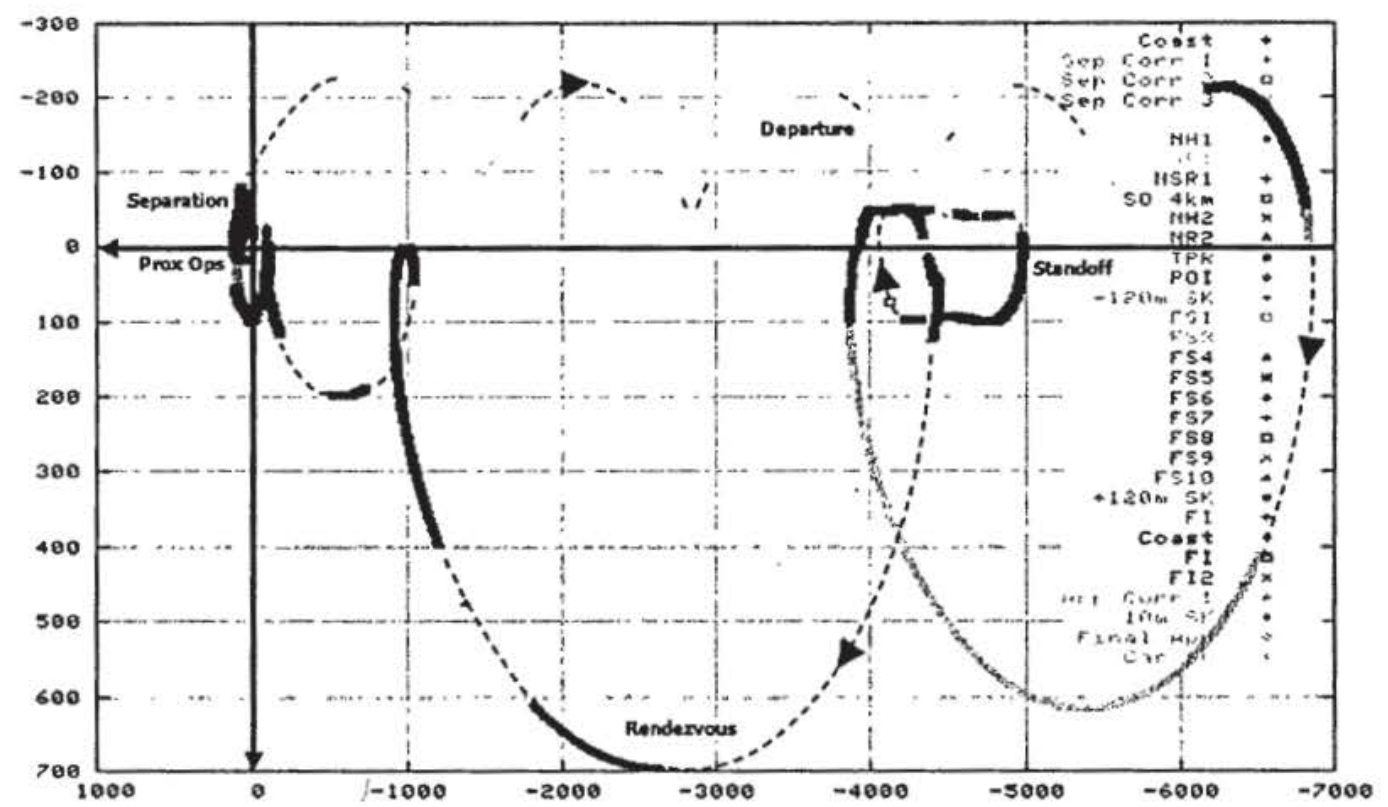

Figure 1315 - Exercise \#5 Actual/Onboard In-Plane Rendezvous Trajectory

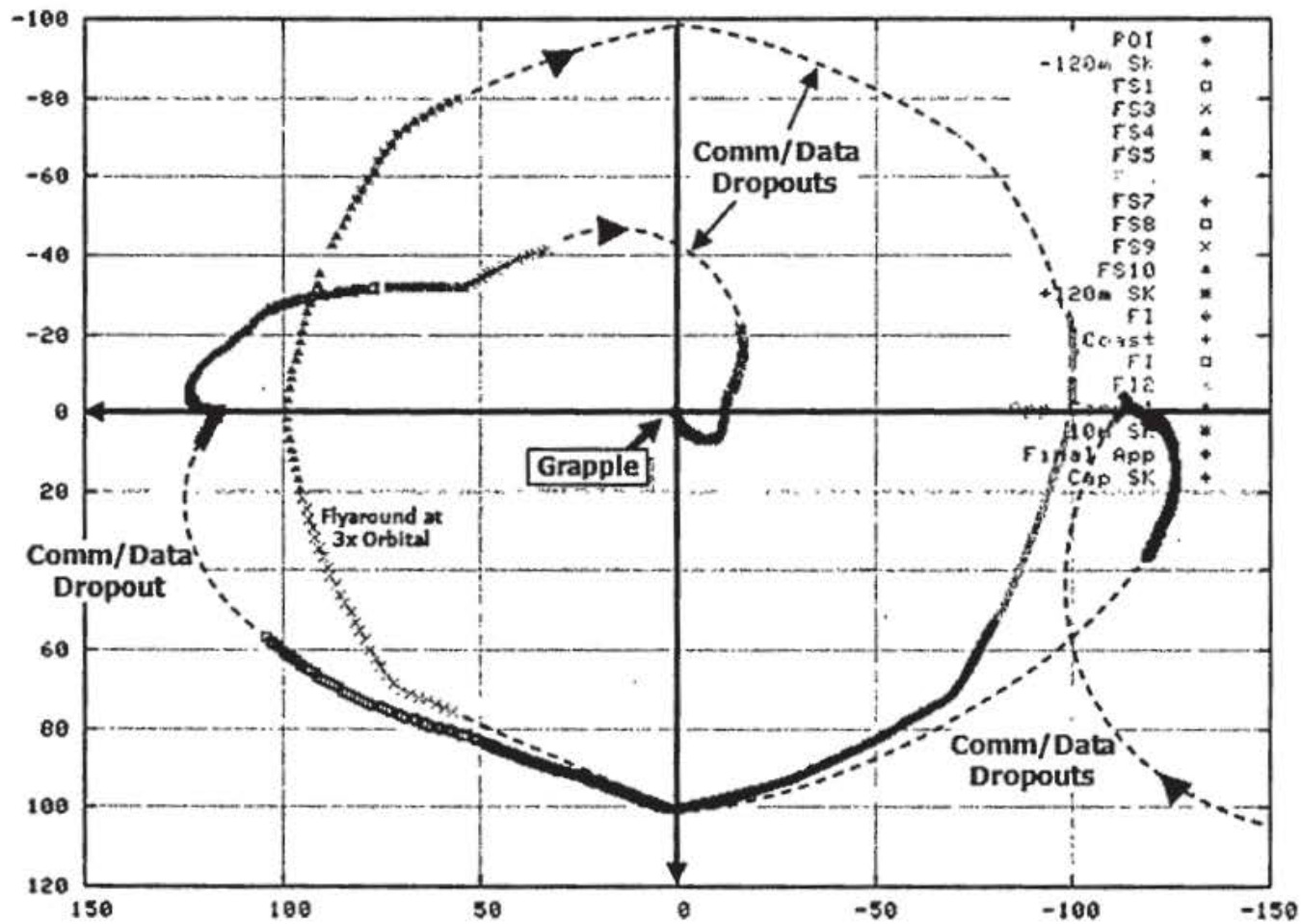

Figure 1416- Exercise \#5 Actual/Onboard In-Plane Proximity Operations Trajectory

\section{Second Generation AR\&C System}

During the three years since OE completion, Boeing has addressed AR\&C issues and lessons learned from the flight; updated to the latest vendor sensors; improved methods for Vis-STAR target modeling; continued improving upon the guidance and navigation algorithms; streamlined the simulation code; and upgraded sensor and avionics laboratories in Huntington Beach and Houston. The resulting second generation AR\&C hardware and software 
expands capabilities and improves robustness in sensor tracking, sensor processing, attitude determination; autonomous guidance; navigation processing; modeling/simulation, and ground test/verification. The OE ground rules of keeping the system generic to virtually any rendezvousing spacecraft, and not requiring assistance from the client satellite or ground, remain.

\section{E. Future Missions}

OE focused on rendezvous with all types of satellites flying in virtually any orbit and attitude. To minimize impacts and costs to future satellite developers, complexity and mass burdens were levied upon the servicing spacecraft, not the client to be serviced. Features and the maturity level found in the OE-derived AR\&C system are clearly relevant to missions requiring autonomous rendezvous. 


\section{Future Potential For Servicing}

In this section we discuss future servicing missions and technologies required to accomplish those missions.

\section{A. Space Servicing Capabilities Project}

In 2009 NASA's Goddard Space Flight Center formed the Space Servicing Capabilities Project (SSCP) to build on experience from the series of successful Hubble Servicing Missions and the work performed for the HRSDM vehicle, by studying future manned and robotic servicing applications and performing flight demonstrations of targeted capabilities relevant to satellite servicing. The SSCP commenced a wide-ranging study to identify servicing stakeholders, including customers and technology providers, and evaluate the readiness of servicing systems, especially including robotics, tools, and sensing technologies. ${ }^{4}$ The SSCP released an RFI, held an international workshop, identified several notional servicing missions and unique system requirements for those missions, and conducted several brief design exercises in the GSFC Mission Design Lab (MDL) to design servicing systems for each notional mission, and evaluate cost and technology readiness for those notional missions. In all, seven notional missions were selected that span several areas of the servicing technology space. The SSCP will submit a report to NASA HQ in the fall of 2010 documenting the results of this study.

In addition to executing the study, in fiscal year 2010 the SSCP commenced efforts on a series of ground and ISS-based demonstrations targeted towards development and verification of required new technologies identified in the FY2009 Study effort, and as risk mitigation for a future servicing mission. In late 2010, SSCP will deliver two ISS payloads to KSC. The first SSCP risk mitigation payload to ISS is a refueling demonstration payload, the Robotic Refueling Dextrous Demonstration(R2D2), which will use ISS robotics to demonstrate tools and robotics tasks required to refuel existing space assets via the fill and drain valves on those vehicles (note these are the ground access fill and drain valves, not originally designed for use in space). The second SSCP risk mitigation payload to ISS is a platform for space-based demonstration at ISS, the Dextre Pointing Package (DPP). DPP will use ISS robotics, and DPP-internal avionics and attitude determination sensors to actively point demonstration payloads (i.e. new sensors, detectors, or other technologies) at a variety of targets, including Earth-fixed, Inertial, ISS-based, or ISS-proximate vehicle targets, enabling inexpensive on-orbit test of a large variety of new technologies, including relative navigation sensors, science-enabling technologies, and other new sensor and detector technologies.

SSCP is evaluating subsequent risk mitigation payloads to ISS, all utilizing Station Infrastructure and robotics, including: an extension of R2D2 to demonstrate a satellite repair task; active and passive relative navigation sensor demonstrations on DPP; a demonstration of autonomous capture of a non-cooperative object; and demonstration of a new consortium robot arm for servicing. These risk mitigation payloads, along with ongoing ground development and demonstrations, will advance servicing technology and demonstrate the Aerospace community's technical readiness to perform space servicing.

\section{B. Servicing Technology Challenges}

As described in preceding pages of this paper, much of the GN\&C and robotics technology required for space servicing is already in place. NASA, DARPA, and the Air Force have conducted several missions demonstrating technology required for rendezvous proximity operations and docking (RPOD). These technologies include relative navigation sensing hardware, robotics hardware and algorithms, and vehicle navigation, guidance and control algorithms used in several manned and robotic missions. Space servicing requires extension of these capabilities to apply them in new orbital regimes and to new targets, including both cooperative vehicles not yet designed, and to cooperative and non-cooperative vehicles already on orbit.

In the GN\&C realm, autonomous capture of non-cooperative vehicles provides the most significant new challenge. Candidate vehicles for servicing offer a wide range of characteristics in terms of cooperation. They may or may not have: active systems such as two-way radios for ranging and data sharing; passive sensing aids such as reflectors or optical targets; capture aids such as grapple fixtures or docking mechanisms; and commandable control modes enabling ground controllers to optimize their orientation and configuration for capture, and perhaps most importantly to disable their attitude control systems during capture and stacked operations. 


\section{Relative Navigation Sensing}

Table 1 - Sensing Requirements shows typical sensing requirements as a function of range for ARPOD operations, as well as the sensor types used by previous missions. The table clearly shows the region where relative navigation sensing of non-cooperative targets has not been fully demonstrated.

Table 1 - Sensing Requirements

\begin{tabular}{|l|l|l|l|l|c|}
\hline \multicolumn{2}{|c}{ Phase } & \multicolumn{1}{c}{ Rensor } & \multicolumn{1}{c|}{ Range of Operation } & \multicolumn{1}{c|}{ Measurement Type } & TRL \\
\hline Orbit & GPS & $\mathrm{R}>100 \mathrm{~m}$ & $\begin{array}{l}\text { Inertial position and } \\
\text { velocity }\end{array}$ & Inertial Position & $8-9$ \\
\hline Orbit & IMU & N/A & $\begin{array}{l}\text { Inertial acceleration and } \\
\text { attitude rates }\end{array}$ & $\begin{array}{l}\text { Propagated Attitude and } \\
\text { Position }\end{array}$ & 9 \\
\hline Orbit & Star Tracker & $\mathrm{R}>2 \mathrm{Km}$ & Catalog Matching & inertial attitude & $8-9$ \\
\hline $\begin{array}{l}\text { Acquisition } \\
\text { Sensor }\end{array}$ & RGPS & $500 \mathrm{~m}<\mathrm{R}<35 \mathrm{~km}$ & $\begin{array}{l}\text { Target and chaser pseudo } \\
\text { and delta ranges }\end{array}$ & Relative pos/vel & $8-9$ \\
\hline $\begin{array}{l}\text { Acquisition } \\
\text { Sensor }\end{array}$ & Optical & $100 \mathrm{~m}<\mathrm{R}<5 \mathrm{Km}$ & $\begin{array}{l}\text { Range and beanng to } \\
\text { target }\end{array}$ & relative pos/vel & 6 \\
\hline $\begin{array}{l}\text { Mid-Range } \\
\text { Sensor }\end{array}$ & $\begin{array}{l}\text { Optical } \\
\text { LIDAR }\end{array}$ & $50 \mathrm{~m}<\mathrm{R}<200 \mathrm{~m}$ & $\begin{array}{l}\text { Relative position and } \\
\text { attitude }\end{array}$ & $\begin{array}{l}\text { target rel pos/vel, attitude, rel } \\
\text { attitude }\end{array}$ & -5 \\
\hline $\begin{array}{l}\text { Docking } \\
\text { Sensor }\end{array}$ & $\begin{array}{l}\text { Optical } \\
\text { LIDAR }\end{array}$ & $\cdots<\mathrm{R}<100 \mathrm{~m}$ & $\begin{array}{l}\text { Relative position and } \\
\text { attitude }\end{array}$ & $\begin{array}{l}\text { target rel pos/vel, attitude rel } \\
\text { attitude }\end{array}$ & $\sim 5$ \\
\hline
\end{tabular}

Numerous previous missions have demonstrated long-range (100s of $\mathrm{km}$, far-field rendezvous) relative sensing of essentially non-cooperative target vehicles: Gemini, Apollo, Shuttle, Orbital Express all used angles-only navigation based on optical or infrared bearing measurements to a passively illuminated target, and were not dependent on cooperation of the target.

At some intermediate range (about $10-20 \mathrm{~km}$, near-field rendezvous), most but not all previous missions acquired some direct range measurement, either with an RF device (Shuttle Rendezvous Radar), or a laser based device (Orbital express laser ranger). Again, these systems could operate in a non-cooperative mode by bouncing a signal off of their essentially passive target.

At short range (less than a few $\mathrm{km}$, proximity operations), most previous missions took advantage of cooperative targets to perform relative navigation sensing. The Space Shuttle Trajectory Control Sensor (TCS, a scanning laser ranger) used a retro-reflective target on Station to measure range and bearing. Orbital Express Advanced Video Guidance Sensor (AVGS, a laser illuminator with 2D imager) used several filtered retro-reflectors to estimate range and bearing at long range and relative attitude at short range. $\mathrm{OE}$ also used a passive vision-based sensor (VisNav), which took advantage of a cooperative optical target shown in Figure 15- NextSat TargetFigure 18-NextSat Target. Similarly, Progress, Soyuz, and ATV all use active systems with cooperative targets or two-way RF devices at short range. 


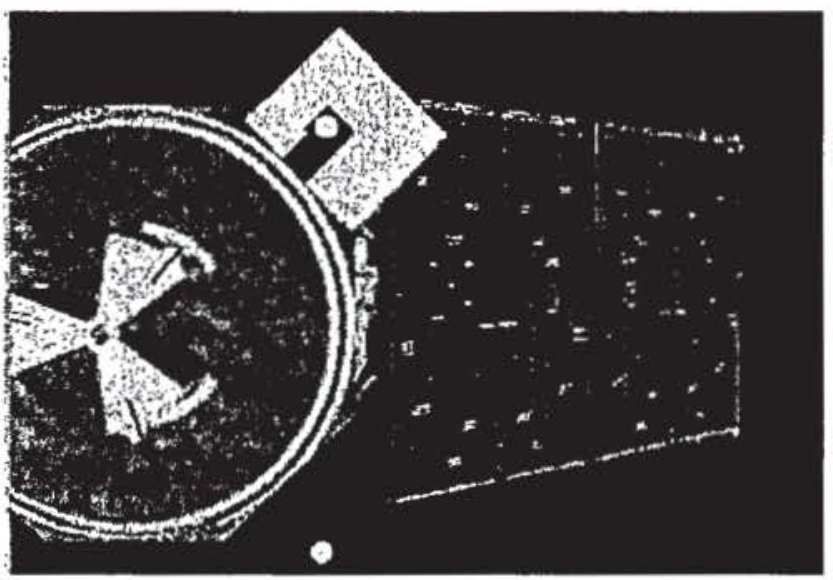

Figure 1518- NextSat Target

There are some examples of less cooperative relative navigation sensing. Space Shuttle proximity operations with Hubble, which prior to Servicing Mission 4 did not have cooperative targets, were performed 5 times using some range measurements from the Shuttle Hand Held Laser ranger, but mostly by direct observation of Hubble by astronauts. Orbital Express performed some proximity operations using non-cooperative sensing including laser | ranger and silhouette feature tracking. Most significantly, Experimental Satellite System11 (XSS-11) performed several close approaches with its Minotaur upper stage and at least one other target using a scanning laser ranger. The XSS-11 targets did not have cooperative sensing aids. At no point did XSS-11 capture a target, however.

More recent efforts in relative navigation sensing include several Shuttle-based experiments. The Hubble Space Telescope (HST) Relative Navigation Sensor (RNS) experiment flew on Space Shuttle Atlantis on HST Servicing Mission 4 in May 2009 and demonstrated passive pose estimation, using monocular cameras to track HST features during rendezvous and deploy ${ }^{5}$ The Neptec TriDAR, consisting of three sensors in one (scanning triangulation device, scanning lidar, and infrared camera) flew to ISS on STS-128 and STS-131 in Aug-Sept 2009 and Apr of 2010 , respectively, and is scheduled to fly again on STS-133 in Oct 2010. TriDAR demonstrated non-cooperative sensing by comparing 3D point clouds of ISS to its internal model and outputting a full 6DOF pose solution (the first non-cooperative laser-based 6DOF pose demonstration). ASC's flash lidar (SpaceX Dragon's primary Proximity operations sensor) was flown on STS-129. Finally, the Sensor Test for Orion RelNav Risk Mitigation (STORRM) unit will fly on STS-134, currently scheduled for early 2011. STORRM includes two of Orion's planned relative navigation sensors: the Ball Docking Camera and the Vision Navigation Sensor (VNS) flash lidar system which uses optical target (DC) and reflectors (VNS) to perform relative navigation.

The message of this section should be clear: no spacecraft has ever performed autonomous capture of noncooperative vehicle, and full $6 \mathrm{DOF}$ relative navigation sensing to non-cooperative vehicles has been shown only to a limited extent (HST RNS, OE, TriDAR DTO). Clearly further work is required to establish a robust, lightinginsensitive solution for all orbit regimes. 


\section{Acronyms}

\begin{tabular}{|l|l|}
\hline AAS & American Astronautical Society \\
\hline AFSCN & Air Force Space Communications Network \\
\hline AIAA & American Institute of Aeronautics and Astronautics \\
\hline AR\&C & Autonomous Rendezvous and Capture \\
\hline ASTRO & Autonomous Space Transport Robotic Operations \\
\hline AVGS & Advanced Video Guidance Sensor \\
\hline DAP & Digital AutoPilot \\
\hline DARPA & Defense Advanced Research Project Agency \\
\hline GSFC & Goddard Space Flight Center \\
\hline HST & Hubble Space Telescope \\
\hline km & Kilometer(s) \\
\hline m & Meter(s) \\
\hline NASA & National Aeronautics and Space Administration \\
\hline OE & Orbital Express \\
\hline R2D2 & Robotic Refueling Dexterous Demonstration \\
\hline R-Bar & Radial Vector \\
\hline RPOD & Rendezvous, Proximity Operations, and Docking \\
\hline RSC & Research, Development, Test, and Evaluation Support Center \\
\hline S & Second(s) \\
\hline STP-1 & Space Test Program 1 \\
\hline STS & Space Transportation System \\
\hline SM & Servicing Mission \\
\hline SSCP & Space Servicing Capabilities Project \\
\hline STORRM & Sensor Test for Orion RelNav Risk Mitigation \\
\hline TDRS & Tracking and Data Relay Satellite \\
\hline V-Bar & Velocity Vector \\
\hline Vis-STAR & Vision-based Software for Track, Attitude, and Ranging \\
\hline XSS-11 & Experimental Satellite System11 \\
\hline & \\
\hline
\end{tabular}

\section{References}

'Manny R. Leinz, Chih-Tsai Chen, Michael W. Beaven, Thomas P. Weismuller, David L. Caballero, William B. Gaumer, Peter W. Sabasteanski, Peter A. Scott, Mark A. Lundgren, "Orbital Express Autonomous Rendezvous and Capture Sensor System (ARCSS) Flight Test Results", AAS 07-408, AAS/AIAA Astrodynamics Specialist Conference, August 2007

${ }^{2}$ Tom A. Mulder, "Orbital Express Autonomous Rendezvous and Capture Flight Operations - Part 1 of 2: Mission Description, AR\&C Exercises 1, 2, and 3"; AAS 08-209; AAS/A1AA Space Flight Mechanics Conference, January 2008

${ }^{3}$ Tom A. Mulder, "Orbital Express Autonomous Rendezvous and Capture Flight Operations - Part 2 of 2: AR\&C Exercises 4, 5, and End-of-Life"; AIAA-2008-6768; AIAAJAAS Astrodynamics Specialist Conference, August 2008

${ }^{4}$ NASA Servicing Study: http://servicingstudy.gsfc.nasa.govl

${ }^{5} \mathrm{~J}$. Van Eepoel, B. Naasz, S. Queen "Flight Results from the HST SM4 Relative Navigation Sensor System," AAS Guidance Navigation and Control Conference, 6-10 February 2010, Breckenridge, Colorado, 10-086 